\title{
ABSENSI KEHADIRAN MENGGUNAKAN KAMERA PENGAWAS BERBASIS TEKNOLOGI COMPUTER VISION
}

\author{
Dedy Armiady \\ 1)Jurusan Sistem Informasi, Fakultas Ilmu Komputer, Universitas Almuslim Bireuen \\ e-mail: dedy.armiady@gmail.com
}

\begin{abstract}
The system can use IP Camera or CCTV, IP Camera requires UTP cable for data communication, while CCTV requires Coaxial cable. Face recognition is carried out through the Face Detection, Feature Extraction and Face Recognition stages, then matched with profile data stored in the database. To detect faces, OpenCV is needed which is embedded into the system. OpenCV is a library (library) that is used to process images and videos so that we are able to extract the information in them. OpenCV can run in various programming languages, such as C, C++, Java, Python, and is also supported on various platforms such as Windows, Linux, Mac OS, iOS and Android. Each user of the Face Recognition Attendance system needs to be registered first 1 (one) at a time, and the system conducts training from the videos of each registered user and a Source Base is made in the form of photos and stored on the server computer as a comparison and detects faces from various camera angles later. The database used is MySQL with the data accommodated are face data information, schedule data, user data and attendance information data. Connections for CCTV use RTSP which is a computer network designed for multimedia needs and data communication systems, which can control the flow of media from the server. This protocol is used to establish and control media sessions between two endpoints. Most RTSP servers use Real-time Transport Protocol (RTP) which is complementary to Real-time Control Protocol (RTCP) for delivery of media streams. Meanwhile, the use of an IP Camera or IP Camera is a camera based on Internet Protocol, a type of digital video camera that receives control data and transmits image data over an IP network. Usually used for surveillance but differs from analog Closedcircuit Television (CCTV) cameras, which do not require a local recording device, but only a local area network. Most IP cameras are webcams, but the term IP camera or Netcam usually only applies to cameras that are directly accessible via a network connection and can be used for surveillance cameras.
\end{abstract}

Keywords: Information System; Face Recognition; Online Attendance; Rapid Application Development; CCTV, IP Camera.

\begin{abstract}
Abstrak
Sistem dapat menggunakan IP Camera maupun CCTV, IP Camera membutuhkan kabel UTP untuk melakukan komunikasi data, sementara CCTV membutuhkan kabel Coaxial. Pengenalan wajah dilakukan melalui tahap Face Detection, Feature Extraction dan Face Recognition, selanjutnya dicocokkan dengan data profil yang tersimpan di dalam Database. Untuk mendeteksi wajah diperlukan OpenCV yang ditanamkan ke dalam sistem. OpenCV adalah sebuah library (perpustakaan) yang digunakan untuk mengolah gambar dan video hingga kita mampu mengekstrak informasi di dalamnya. OpenCV dapat berjalan di berbagai bahasa pemrograman, seperti C, C++, Java, Python, dan juga didukung di berbagai platform seperti Windows, Linux, Mac OS, iOS dan Android. Setiap pengguna sistem Absensi Face Recognition perlu dilakukan registrasi terlebih dahulu 1 (satu) persatu, dan sistem melakukan Training dari video setiap pengguna yang didaftarkan dan dibuat Source Base dalam bentuk foto dan disimpan di komputer server sebagai menjadi pembanding dan mendeteksi wajah dari berbagai sudut kamera nantinya. Database digunakan adalah MySQL dengan data yang ditampung adalah informasi data wajah, data jadwal, data User serta data informasi absensi. Koneksi untuk CCTV menggunakan RTSP yang merupakan jaringan komputer yang dirancang untuk kebutuhan multimedia dan sistem komunikasi data, yang dapat yang dapat mengendalikan aliran media dari server. Protokol ini digunakan untuk menetapkan dan mengendalikan sesi media antara dua titik ujungnya. Sebagian besar server RTSP menggunakan Real-time Transport Protocol (RTP) yang saling melengkapi dengan Real-
\end{abstract}


time Control Protocol (RTCP) untuk pengiriman aliran media. Sementara itu penggunaan IP Camera atau Kamera IP adalah kamera dengan basis Internet Protocol, jenis kamera video digital yang menerima data kontrol dan mengirimkan data gambar melalui jaringan IP. biasanya digunakan untuk pengawasan tetapi berbeda dengan kamera analog Closed-circuit Television (CCTV), yang mana tidak memerlukan perangkat perekaman lokal, namun hanya jaringan area lokal. Kebanyakan kamera IP adalah Webcam, tetapi istilah kamera IP atau Netcam biasanya hanya berlaku untuk kamera yang dapat langsung diakses melalui koneksi jaringan dan dapat digunakan untuk kamera pengawasan.

Kata Kunci: Sistem Informasi; Face Recognition; Absensi Online; Rapid Application Development; CCTV, IP Camera.

\section{Pendahuluan}

Perkembangan teknologi telah banyak memberikan kemudahan dalam kesejahteraan umat manusia, baik dalam dunia pendidikan, perbankan, kesehatan dan lain sebagainya. Di samping itu kemajuan teknologi tidak luput dari tindak kriminal yang sering disebut Cyber Crime (tindak kejahatan dunia maya) atau kecurangankecurangan lainnya yang dapat merugikan pihak tertentu, misalnya pemanipulasian data, hal tersebut masih sering terjadi, maka diperlukan antisipasi yang dapat mengurangi kecurangan-kecurangan.

Dalam dunia kerja, absensi merupakan salah satu hal inti dan vital yang wajib diperhatikan demi menjaga kedisiplinan dan produktivitas seorang karyawan atau pekerja. Upaya tersebut dilakukan dengan disediakannya absen kehadiran, baik dengan cara tanda tangan, pindai sidik jari atau pun pendeteksi wajah. Setiap metode absensi tersebut memiliki kelebihan dan kekurangan tersendiri.

Absensi konvensional dengan tanda tangan kehadiran memiliki kelebihan dari sisi Resource yang diperlukan adalah lebih kecil, namun potensi kecurangan dan lebih besar. Absensi sidik jari memiliki lebih sedikit peluang kecurangan, namun sangat tidak praktis dalam hal pelaporan, dikarenakan rekapitulasi harus dilakukan secara manual dan tidak Real Time, sehingga kondisi tersebut menjadi celah untuk terjadinya manipulasi data kehadiran ketika rekapitulasi dilakukan secara manual.

Absensi yang dapat dipantau secara Real Time dapat memberikan kemudahan kepada HRD (Human Resources Development) atau pimpinan untuk melihat informasi kehadiran karyawan secara langsung via daring (berbasis Online) di samping itu rekapitulasi absensi yang dapat dibuat secara otomatis oleh sistem tentu akan sangat menguntungkan, hemat waktu serta kecil kemungkinan kecurangan, hal lainnya yang diharapkan adalah memudahkan klien atau pengguna serta mendukung program pemerintah untuk jaga jarak dan meminimal bersentuhan di masa pandemi.

Kemudahan tersebut dapat diwujudkan dengan membangun sebuah absensi pemindai wajah jarak menengah menggunakan kamera pengawas berbasis Online. CCTV pada umumnya telah banyak terdapat di instansi-instansi pemerintah maupun swasta yang sebelumnya maksudkan untuk memantau lingkungan kerja agar dapat mengurangi terjadinya hal-hal yang tidak diharapkan.

\section{Metode}

A. Metode Pengembangan Sistem

Rapid Application Development (RAD) pertama kali diusulkan oleh konsultan komputer James Martin pada tahun 1991. Ini adalah metode pengembangan terstruktur yang mencoba menghasilkan sistem dengan cepat tanpa mengorbankan kualitas.

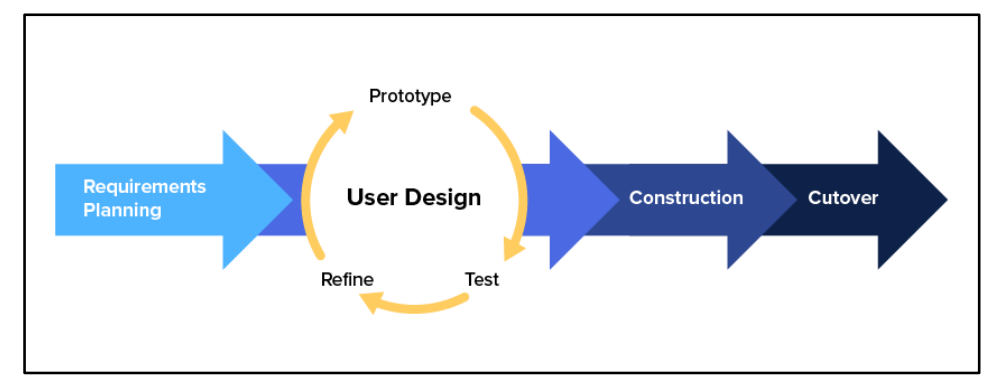

Gambar 1. Siklus Rapid Application Development.

RAD memiliki tujuan yang sama dengan metode prototipe - untuk merespons kebutuhan pengguna dengan cepat, akan tetapi memiliki cakupan yang lebih luas. Metode ini banyak digunakan di bidang TI tingkat lanjut di seluruh dunia. Tujuan RAD adalah membangun perangkat lunak bisnis yang memenuhi kebutuhan 
pengguna dalam waktu singkat, yaitu 60 hingga 90 hari. Model ini memungkinkan pengembang untuk membuat banyak iterasi dan pembaruan perangkat lunak dengan cepat, dan tidak perlu memulai dari awal setiap ada pengembangan.

RAD semacam model inkremental yang menekankan siklus pengembangan agar lebih singkat dan padat. Model ini merupakan varian kecepatan tinggi dari model Waterfall, yang mana berbasis penggunaan ekstensif komponen yang dapat revisi secara terpisah jika diperlukan perbaikan atau pengembangan. Jika pengembang dapat memahami persyaratan dengan benar dan membatasi ruang lingkup proyek pada saat yang sama, maka dapat dengan cepat dibuat sistem informasi yang berfungsi penuh dengan menggunakan model Rapid Application Development. Proses dimulai dengan pemodelan bisnis, diikuti oleh pemodelan data, pemodelan proses, pembuatan aplikasi, pengujian, dan iterasi. Adapun rincinya adalah sebagai berikut:

1) Pemodelan bisnis

Identifikasi informasi yang berjalan sesuai proses bisnisnya, cara menghasilkan informasi, arah aliran informasi dan pemrosesannya, dan lain sebagainya. Hal ini dapat dilengkapi dengan Diagram Aliran Data

2) Pemodelan data

Untuk mendukung aliran data proses bisnis, temukan kumpulan data dan tentukan atribut data. Kemudian bentuk model data dengan data lain, yang dapat dilengkapi dengan Entity Relationship Diagram

3) Pemodelan proses

Objek data melengkapi berbagai fungsi bisnis dalam aliran informasi, menciptakan proses untuk menggambarkan penambahan, modifikasi, penghapusan, dan pencarian data. Tujuannya untuk menyempurnakan pemrosesan dalam Diagram Aliran Data.

4) Pembuatan aplikasi

Gunakan bahasa pemrograman yang mutakhir dan fleksibel di berbagai Platform untuk menulis program pemrosesan. Gunakan kembali komponen yang ada atau buat komponen baru yang dapat digunakan kembali.

5) Pengujian

Uji sistem yang baru dibuat sesuai dengan skema kerja dan alur yang ada pada bisnis proses.

B. Kebutuhan Pembangunan Sistem

1) Pendukung

Dibutuhkan berupa komponen Library pendukung dalam pengembangan sistem absensi ini yaitu OpenCV, merupakan adalah sebuah File Library yang digunakan untuk mengolah gambar dan video hingga kita mampu mengekstrak informasi di dalamnya. OpenCV dapat berjalan di berbagai bahasa pemrograman, seperti C, C++, Java, Python, dan juga mendukung di berbagai platform seperti Windows, Linux, Mac OS, iOS dan Android.

2) Perangkat Lunak

Bahasa pemrograman yang digunakan adalah Python dan PHP (berbasis Framework CodeIgniter). PHP digunakan sebagai bahasa pemrograman utama untuk mengelola data kehadiran dan pembuatan laporan rekapitulasi data kehadiran, dan Python dibangun jembatan antar sistem pengelolaan data kehadiran dengan perangkat perekam wajah berupa kamera.

3) Perangkat Keras

Terdapat beberapa komponen perangkat keras yang dibutuhkan di antaranya, kamera (IP Camera atau CCTV), kabel (kabel UTP atau Coaxial), Komputer Server, HUB Switch serta 1 (satu) unit komputer.

C. Kerangka sistem

Sistem absensi berbasis Face Recognition membutuhkan koneksi internet secara kontinu untuk dapat beroperasi, di samping itu diperlukan juga sebuah basis data pada server untuk menampung data absensi serta informasi data pengguna. Pada gambar 2 diilustrasikan rancangan mekanisme kerja sistem secara keseluruhan.

D. Ilustrasi Sistem

Sistem Absensi Face Recognition ini dapat menggunakan dua jenis kamera, pertama menggunakan IP Camera dan yang kedua adalah dengan menggunakan CCTV analog, perbedaan keduanya pada jenis data yang dikirim, yaitu digital dan analog, jenis kabel yang digunakan pun berbeda. Pada gambar 3 diilustrasikan struktur dari sistem.

E. Ruang lingkup Sistem Informasi

Agar diketahui luasnya sistem serta entitas yang dilibatkan maka perlu dibuatkan ilustrasi dari sistem absensi yang dibangun, berikut desain Konteks Diagram sistem secara keseluruhan. 


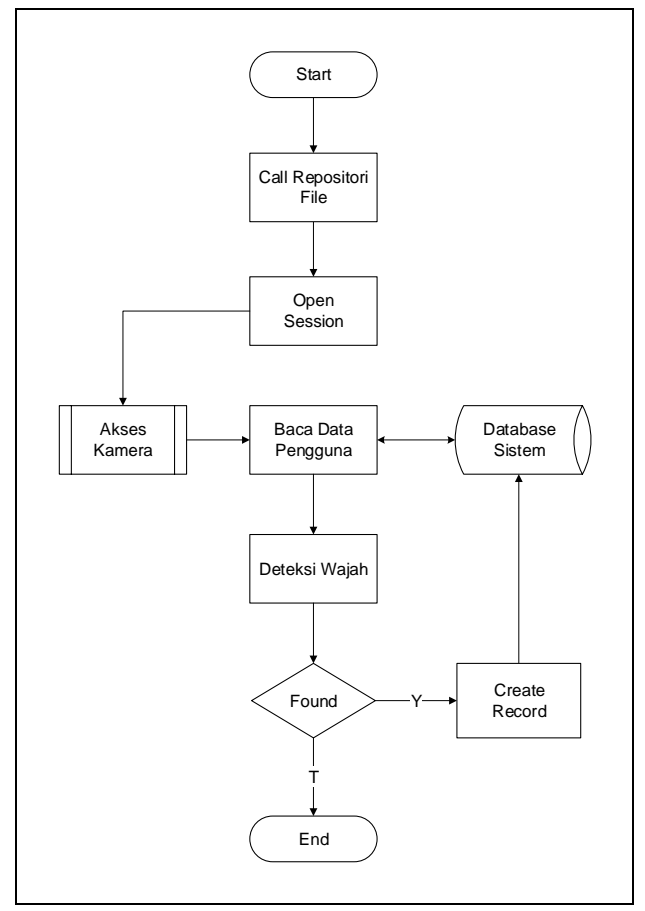

Gambar 2. Flowchart alur sistem seacara umum

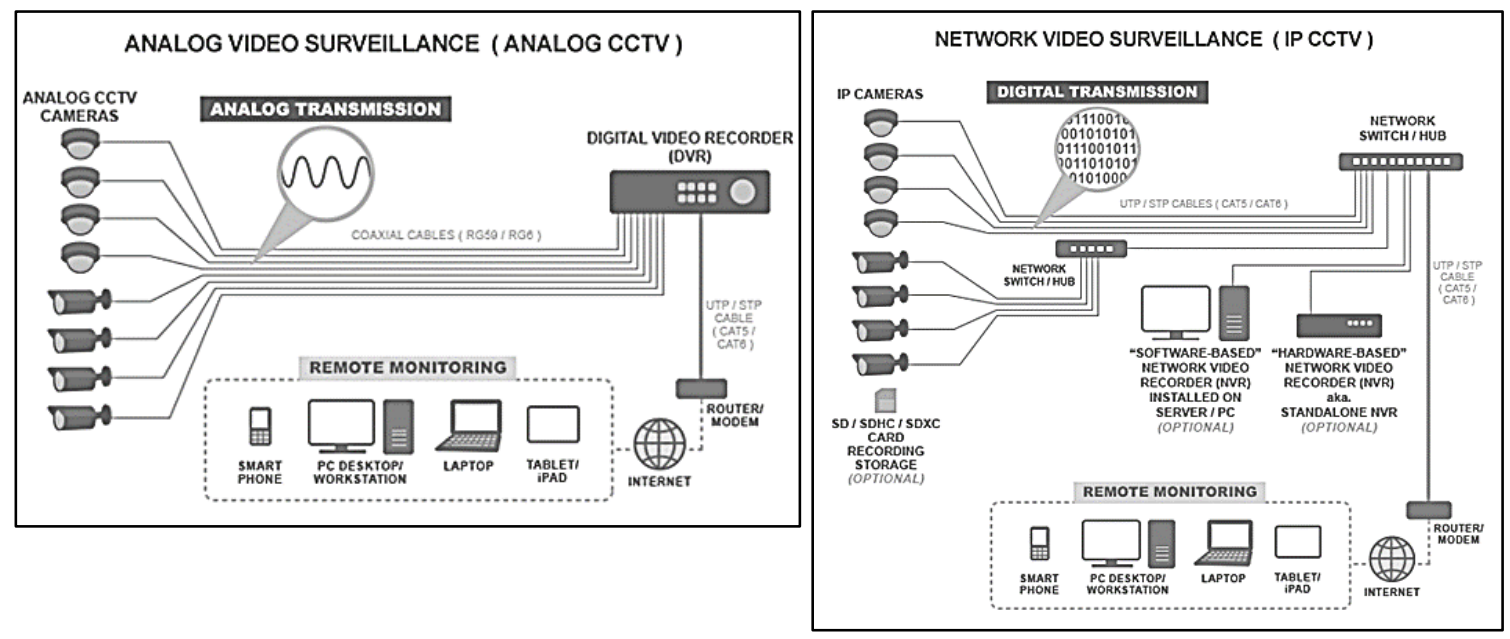

Gambar 3. Skema atau struktur sistem secara umum

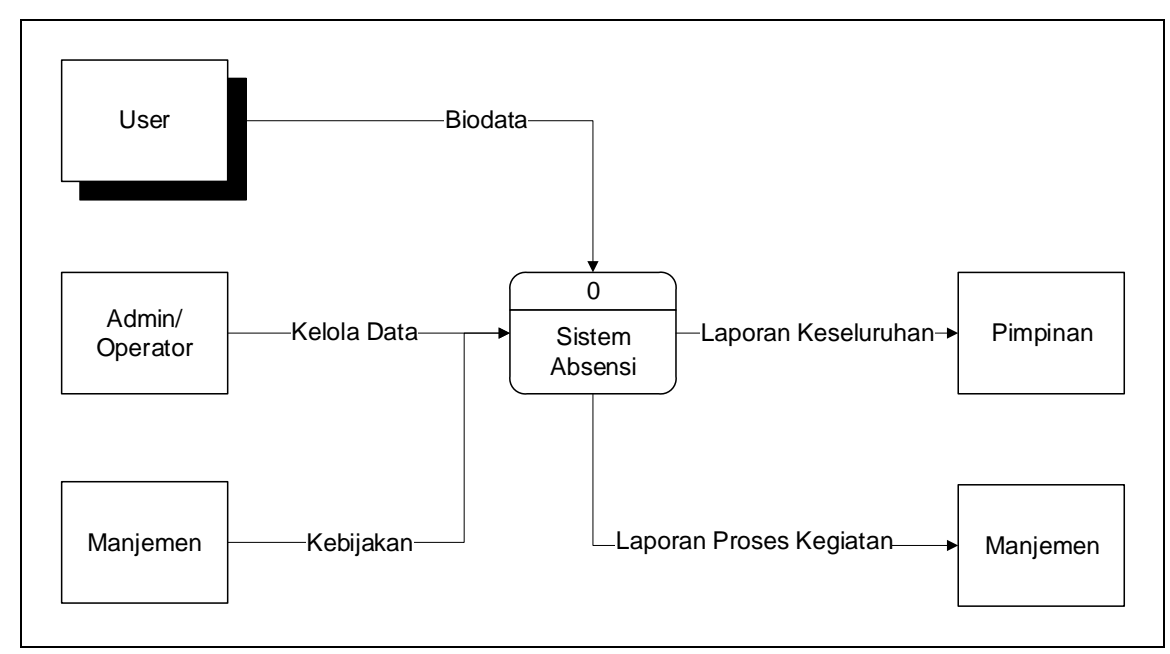

Gambar 4. Skema sistem secara keseluruhan 
Aktivitas absensi serta penjadwalan absensi diperlukan media simpan dan sarana untuk mengelolanya, berikut struktur desain Database untuk sistem yang dibangun.

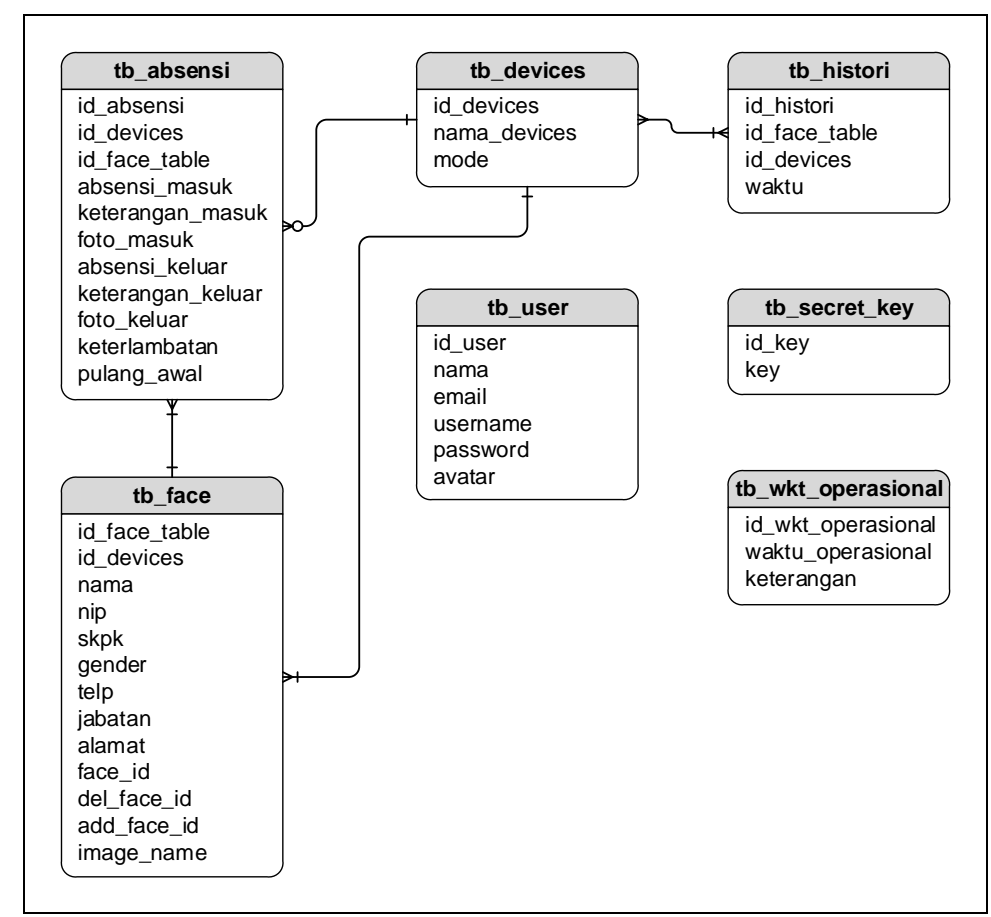

Gambar 5. Struktur Tabel dalam Database

\section{Hasil dan Pembahasan}

A. Implementasi

Dibutuhkan koneksi internet untuk menjalankan sistem absensi secara maksimal. Pada server terpasang sistem informasi absensi yang bekerja secara Real Time dan kontinu, sistem akan aktif sesuai jadwal yang ditentukan dalam Database. Dibutuhkan URL atau domain untuk alamat dari sistem yang dibangun.

Sebelum sistem dijalankan, terlebih dahulu perlu dilakukannya registrasi data User, data wajah dan informasi kamera (lokasi dan sejenisnya). Berikut tampilan aplikasi pendataan wajah User yang dibangun menggunakan Python.

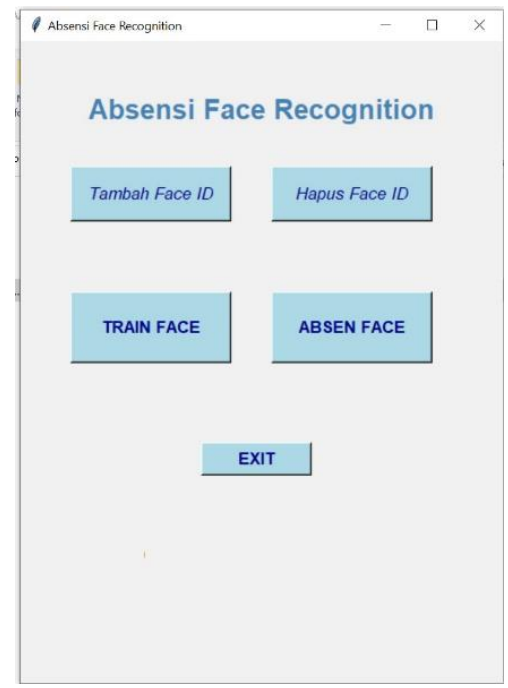

Gambar 6. Tampilan aplikasi registrasi wajah

User yang diregistrasikan perlu dilakukan pemindaian wajah, berikut tampilan pemindaian wajah User yang diuji dengan menggunakan Kamera IP. 


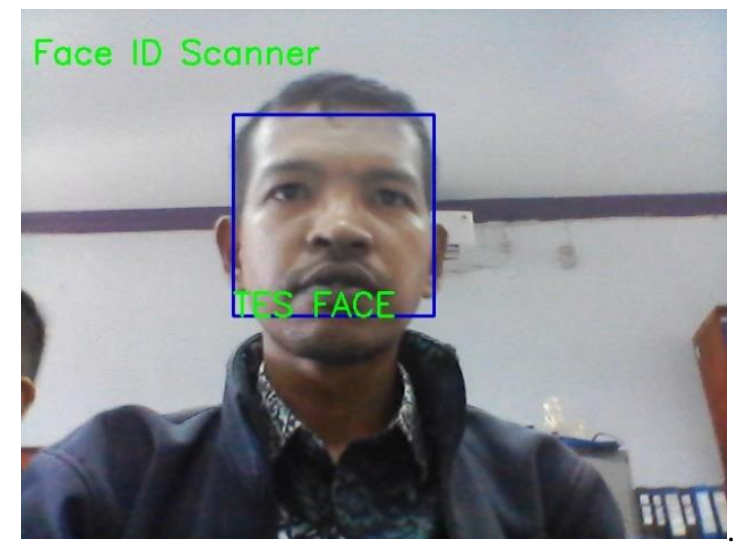

Gambar 6. Tampilan pemindaian wajah untuk registrasi wajah

Setelah seorang User berhasil dilakukan pemindaian wajah dan didata Face ID ke Database, maka User tersebut akan dideteksi dan dikenali tiap melalui kamera pengawas yang terhubung ke sistem. Berikut hasil yang didapatkan dari pengujian.

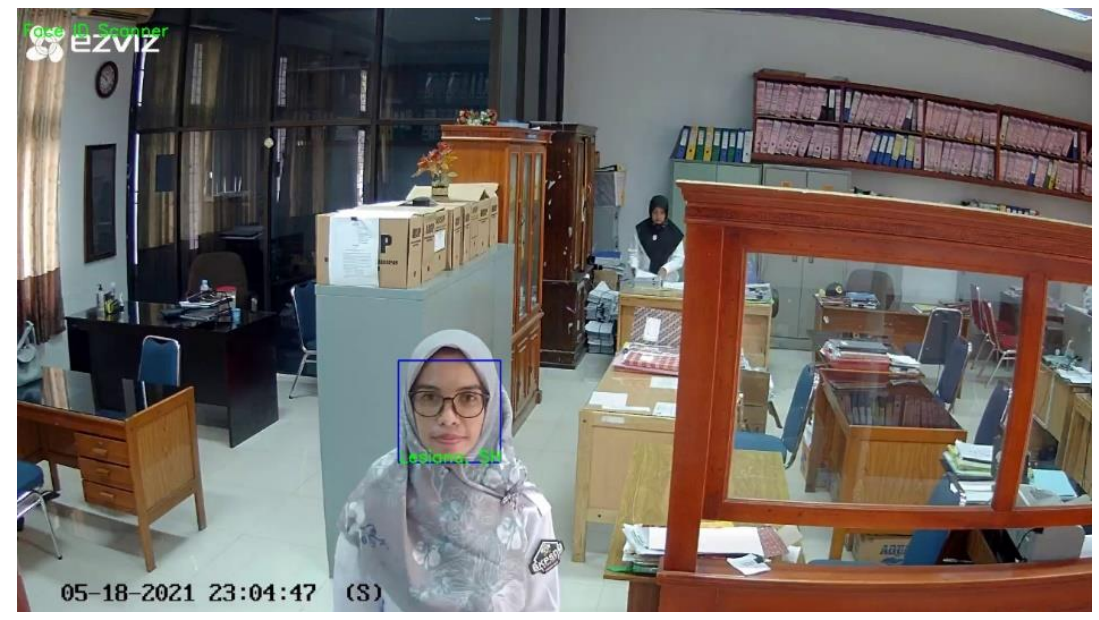

Gambar 6. Tampilan pemindaian wajah untuk registrasi wajah

Data di atas dapat dikelola dan dipantau melalui aplikasi berbasis web yang berjalan secara Online yang telah dibangun dengan menggunakan bahasa pemrograman PHP dengan Framework CodeIgniter. Berikut adalah tampilan halaman dasbor admin.

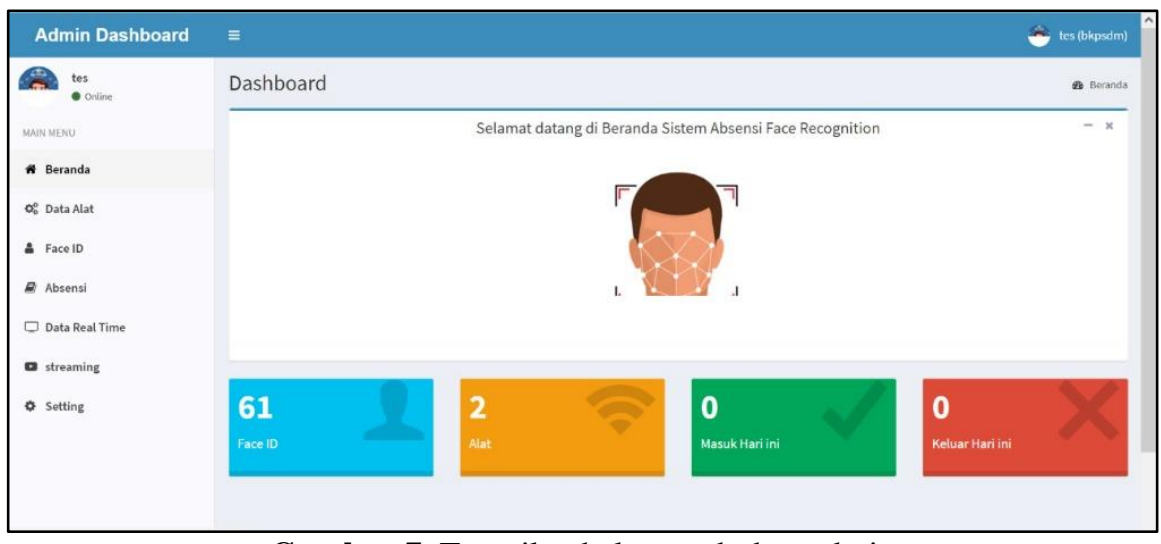

Gambar 7. Tampilan halaman dasbor admin

B. Prinsip Kerja

Setiap User yang melalui atau melewati titik yang telah dipasangkan kamera maka akan terbaca secara otomatis data User tersebut. Dan pencatatan absensi dilakukan pada 2 (dua) waktu, yaitu pagi (jam masuk) dan sore (jam pulang), keduanya dapat ditentukan secara spesifik untuk pukul yang diinginkan melalui sistem informasi berbasis webnya. 


\section{A. Kesimpulan}

Setelah melalui beberapa tahap dalam penelitian yang meliputi, perancangan, pembuatan, dan pengujian, maka dapat diambil kesimpulan sebagai berikut:

1) Sistem dapat digunakan lebih dari satu titik kamera pengawas untuk melakukan absensi

2) Diperlukan cahaya yang cukup untuk dapat mendeteksi wajah dengan baik

3) Penggunaan IP Camera lebih disarankan

\section{Daftar Pustaka}

Anggraini, N., Rozy, N. F., \& Lazuardy, R. A. (2013). Facial Recognition System For Fatigue Detection Using Intel Realsense Technology Departement of Informatics Engineering Faculty of Science and Technology State Islamic University of Syarif Hidayatullah Jakarta. (may).

Emami, S., \& Suciu, V. P. (2012). Facial Recognition using OpenCV. Journal of Mobile, Embedded and Distributed Systems, 4(1), 38-43. Retrieved from http://www.jmeds.eu/index.php/jmeds/article/view/57

Ivanjul.com. (2018). Fungsi Membaca, Menampilkan, dan Menyimpan Gambar OpenCV Python. Retrieved December 21, 2019, from https://www.ivanjul.com/fungsi-membaca-menampilkan-dan-menyimpangambar-opencv-python/

Kurniawan, D. E., \& Fani, S. (2017). Perancangan sistem kamera pengawas berbasis perangkat bergerak menggunakan raspberry pi. Jurnal Ilmiah Teknologi Informasi Terapan, III(2), 140-146.

Mjrovai. (n.d.). Real-time Face Recognition: an End-to-end Project: 8 Steps (with Pictures). Retrieved January 5, 2020, from https://www.instructables.com/id/Real-time-Face-Recognition-an-End-to-endProject/

OpenCV. 2018. Face Detection using Haar Cascades. https://docs.opencv.org/3.4.1/d7/d8b/tutorial_py_face_detection.html. 11 Februari 2019. 